\title{
The Impact of Teaching Philosophy for Children on Critical Openness and Reflective Skepticism in Developing Critical Thinking and Self-Efficacy
}

\author{
Aniseh Rahdar \\ MA Student of Educational Research, University of Sistan and Baluchestan, Iran, \\ masoud4828@gmail.com
}

\begin{abstract}
Abdulwahab Pourghaz
Assoc. Prof., corresponding author, Faculty of Educational Sciences and Psychology, University of Sistan and Balcuhestan, Iran,w.pourghaz@ped.usb.ac.ir
\end{abstract}

\section{Afsaneh Marziyeh}

Assoc. Prof., Faculty of Educational Sciences and Psychology, University of Sistan and Balcuhestan, Iran, marziyeh@ped.usb.ac.ir

\begin{abstract}
This study aimed to examine the impact of teaching philosophy for children in developing critical thinking and self-efficacy among students. The current study had a statistical population constituting of all female first-grade junior high school students in Khash in the academic year 2017-2018. Among these students, a corpus of 54 students (27 people assigned to an experimental group and 27 people assigned to a control group) was selected as a sample using a convenience sampling method. The experimental group was taught philosophy; however, the control group did not receive any training. To collect data, Sosu Critical Thinking Disposition Scale and Muris et al. Self-Efficacy Questionnaire for Children and Adolescents were used. For data analysis, using descriptive statistics, means and standard deviations were calculated and by applying inferential statistics, initially, differences between pretest and posttest scores were calculated and these differences between the scores obtained by the control and experimental groups were determined by conducting an independent t-test. Results indicated that there were significant differences in components of critical thinking, critical thinking, and self-efficacy between these two groups. In other words, teaching philosophy for children had a positive impact on increasing self-efficacy, critical thinking, and its components (critical openness and reflective skepticism).
\end{abstract}

Keywords: teaching philosophy for children, critical thinking, critical openness, reflective skepticism, self-efficacy

Citation: Rahdar, A., Pourghaz, A., \& Marziyeh, A. (2018). The Impact of Teaching Philosophy for Children on Critical Openness and Reflective Skepticism in Developing Critical Thinking and SelfEfficacy. International Journal of Instruction, 11(3), 539-556. https://doi.org/10.12973/iji.2018.11337a 


\section{INTRODUCTION}

Having an interest in developing intellectual abilities is not a phenomenon which has just been considered in the present era. This interest is rooted in the history of education. Unfortunately, these days, schools are more focused on transferring scientific information and facts rather than training intellectual and creative human beings (Sha'bani\&Bakhtiari, 2004). If preparing children for future challenges is considered as a goal, a number of special skills should be taught to them, based on which they can dominate their lives and levels of learning. To this end, they need knowledge; however, more importantly, they need abilities to acquire new knowledge. Indeed, they require a kind of knowledge that they can produce and reproduce by themselves (Fisher, 2007).

In recent years, this way of thinking, commonly referred to as philosophy of activity, has been paid significant attention (Smith, 1998). Given two various viewpoints on philosophy, philosophy can be taught in two different ways. Based on the first viewpoint, teaching philosophy is a way to transfer philosophical thoughts to learners. This is while according to the second viewpoint, teaching philosophy aids people to learn how to think (Ghaedi, 2007).

In the last few decades, philosophy has been paid attention once again as a way of fostering the power of thought. In Iran, paying attention to this issue has been raised for about a decade. In this regard, a program known as teaching philosophy for children was presented in the United States and used around the world. Philosophy for children is a kind of applied philosophy. Its main objective is to help students to apply philosophy and aid them to move from a normal state to a thoughtful state, from being indifferent to being thoughtful, and from common thinking to critical thinking. In this program, an exploratory approach is considered. Applying collective inquiry and using Socratic argumentationare determined as parts of its major methodology (Hatami, Karimi, \& Nouri, 2010). Lipman and his colleagues at Montclair University developed the first curriculum on teaching philosophy for children. Initial examinations of this curriculum begun in 1969. So far, it has become a complete curriculum for an entire school year. This curriculum can be applied to students studying at first- to twelfth-grade (Ghaedi, 2007). The main objective of this curriculum is to turn children into more thoughtful, flexible, considerate, and logical human beings (Fisher, 2007). Therefore, it puts an emphasis on complex cognitive skills (e.g. explaining, evaluating, reviewing, differentiating, criticizing, and the like) and preparing the grounds for a number of capabilities (e.g. curiosity, mental openness towards others, acceptance, and the like) (Daniel \&Auriac, 2011).

For implementing teaching philosophy for children, specific storybooks have been published for children and adolescents. In fact, these stories stimulate thinking, questioning, and critical thinking among children. These stories are stimuli for institutionalizing philosophy among children and they offer philosophy by experiencing imaginative characters. Hence, they provide opportunities to address children's moral imaginations. This is why, in this program, the use of philosophical stories has a special place for developing children's moral judgments (Marashi et al., 2010). A community of inquiry is one of the major components of philosophy for children which was introduced 
by Charles Sanders Peirce for the first time. In the community of inquiry, by paying special attention to others or respecting each other, students listen to what other people say and question other people's words to find reasons to prove unconfirmed ideas. In this way, they help each other extract results of what was mentioned and seek to clarify and recognize others' assumptions. The community of inquiry attempts to continue inquiries to the point that they will reach a conclusion and it has nothing to do with the boundaries considered for a curriculum. In the community of inquiry, a dialogue takes place and proceeds to logic. As a result, when this process is internalized or unconsciously transmitted to participants, it aids them to think that they can benefit from what they have learned in other aspects of their lives and in the face of new and real-life events (Naji, 2008). To move towards making use of philosophy and teaching critical thinking, philosophy for children and adolescents can perhaps be regarded as the most recent and the greatest step that has been taken to reinforce and enhance argumentative, reasoning, and screening skills. It is a very good example of applying philosophy in education and its purpose is different from other philosophical programs. It does not aim to clarify philosophical issues for non-philosophers and solve its problems; however, it attempts to help students to do some intellectual activities and solve their own problems (Lipman, 1988).

Although the new educational pattern has laid a great emphasis on promoting intellectual skills, such as questioning and critical thinking, among students, this insight has failed to overcome presumptions of the traditional method of education. Measures taken to teach thinking skills will only be effective when the quality of teacher-student and student-teacher dialogues in a classroom undergo some changes. However, making such changes is really difficult (Topping \&Trickey, 2004).

In a classroom, the philosophical community of inquiry looks for opportunities to aid students to make a point by doing continuous judging exercises. To this end, emotions, thoughts, and feelings are equally important (Naji, 2010). Accordingly, the following items happen as a result of a community of inquiry.

1. Developing an ability to discover assumptions and question apparently obvious things: By having a conversation, children become able to question even seemingly obvious things. The conversation reveals difficulties of various issues which at first seem really simple and obvious. In such conversations, children learn and/or experience that they can always question things (Pazouki\&Heidari, 2011).

2. Recognizing different viewpoints: In a community of inquiry, children indicate that various viewpoints can bring about new experiences to them. Therefore, they learn that they should not only respect various viewpoints and differences of opinions but also seek such differences and welcome them. In this way, children learn that hearing is always more important than saying something (ibid).

3. Learning an ability to critically analyze causes and analogies: The logic behind having a dialogue is asking and answering questions. This logic encourages children to not imitate others and not accept things blindly. Moreover, ithelps them give reasons for accepting or rejecting an idea. On the other hand, they learn to criticize 
other people's opinions by asking and answering questions and measure their strengths (ibid).

Critical thinking skills are defined as abilities to objectively analyze existing information by considering personal experiences and identifying the impact of social values, peers, and media on a person's behavior (Fatti et al., 2006).To judge and/or review and improve the quality of a judgment, a person employs a set of cognitive skills known as cognitive thinking skills. These skills include analysis, interpretation, inference, explanation, evaluation, and self-regulation (Facione et al., 1995).

Morehouse (2010) believes that a method of collective inquiry and argumentation is used in classrooms in which philosophy for children is taught. Students learn to be honest, flexible, and reasonable and respect other people's ideas and opinions. This is why a number of skills, including collective inquiry, thinking, socialization, having a sense of success and morale, is strengthened among these students. They learn to accept or reject different opinions with reasons and that there is no absolutely correct answer when hearing comments and expressing ideas (Morehouse, 2010). Unfortunately, despite laying an emphasis on thinking in goals considered for educational systems and claims of officials, trainers, and education administers, in practice, there is not enough incentive to encourage students to think and, in particular, apply critical thinking. Teachers, in spite of statements that suggest acceptance of this assumption that critical thinking paves the way for good education, always provide a framework in which facts are eliminated and create a disciplined environment for memorizing information (Sha'bani\&Bakhtiari, 2004). Paolo Feria, one of the contemporary critical thinkers, considers critical thinking as the main goal of education. Instead of the term thinking, he uses the term reflection and criticizes the conventional educational system and states that education has become a kind of storage practice in which, instead of establishing a bilateral communication, students store information in their minds like a container and teachers put such information in their containers. In this system, teachers provide some notes and students patiently receive, memorize, and repeat them. This is known as banking model of education in which students' practice range is limited to receiving, filling, and storing information. Feria, as another way to curriculum planning, proposes an emancipating approach. In this approach, the main emphasis is on critical reflection based on objective facts in a person's life. Contrary to the banking model of education, the problem-based approach proposed by Feria involves exchanges of ideas and thoughts through dialogue. In this approach, a teacher and his/her students are all involved in the process of critical reflection. Hence, they are motivated to apply critical reflection in various aspects of their lives. This process ultimately leads to praxis, i.e. taking action based on critical reflection, which is considered as a goal in the Feria's approach (Pozter, 1993). Self-efficacy beliefs are judgments about how much a person believes that he/she can work to achieve a goal or effectively handle a challenging situation (Di Giunta et al., 2013). The better the thinking skills, the better a person can evaluate herself/himself. This may positively affect self-efficacy since evaluating levels of self-efficacy requires cognitive skills including analytical and thinking skills. The more the levels of these skills, the more accurate a person's evaluation of his/her abilities. In this regard, it is expected that there be a correlation between thinking skills 
and self-efficacy (Gloudemans, 2013). Accordingly, by developing critical thinking and self-evaluation skills, philosophy for children, as a goal, can be effective in creating selfefficacy.

Regarding the importance of critical thinking and self-efficacy in education, this study sought to answer the following question: Does teaching philosophy for children have an impact on critical thinking and its components (critical openness and reflective skepticism) and self-efficacy among students?

\section{Review of Literature}

Critical thinking was defined in many different ways. These definitions indicate differences in viewpoints on the concept. Chat Myers, the author of a book entitled "Teaching Critical Thinking", believes that critical thinking is an ability to regulate general abilities, create an analytical framework, accept new possibilities, avoid prejudices and stop judging others (have a healthy doubt and avoid a rush to judgment) (Myers, 1995). Paul and Elder, experts in critical thinking, define it as the art of thinking about your thoughts when you think to improve your thoughts. This aids you to make your thought clear, accurate, and justifiable (Paul \& Elder, 2000). Moore and Parker argue that critical thinking is a deliberate and conscious determination of acceptance, rejection, and/or judgment (AbbasiYadkouri, 2002).

According to Lipman (2003), critical thinking facilitates judgments, since it relies on a set of criteria and rules, leads to self-correction, and is relatively sensitive to context. Hashemiannejad(2001) defined critical thinking as a thoughtful and logical thinking aimed to examine and reconsider beliefs, opinions, actions, and decisions made about them based on reasons and evidence supporting them and their logical and correct outcomes.

In psychology and psychiatry, self-efficacy was introduced as a person's beliefs about his/her ability to cope with different situations (Pourafkari, 1997). Self-efficacy does not refer to a motivationoraneed to restrain that motivation. While a person can have a strong need to control a specific situation, his/her inadequate self-efficacy beliefs can dominate him/her in that same situation. Self-efficacy beliefs refer to a person's beliefs based on which he/she believes that by conducting a specific behavior, he/she can bring about a specific consequence. Self-efficacy beliefs are not simple predictions about behaviors and they do not deal with what a person wants to do. However, they deal with what that person can do (AliniaKarouei, 2003). Self-efficacy beliefs are the most important mechanisms used in a human cognitive function. Indeed, people's beliefs about their desires to exercise control over life-related events are known as self-efficacy beliefs (Bandura, 1997).

\section{Theoretical Foundation and Research Background}

\section{Studies Conducted in Iran}

Jahani (2001), in a research, examined and criticized philosophical foundations of Lipman's critical thinking model. Although he did not explicitly discuss teaching philosophy for children, he introduced it as a part of his research background. Jahani 
stated that the main objective of conducting this study was to examine underlying assumptions and foundations of the Lipman's model. To this end, he initially discussed contextualism and proportionality which were really liked by Lipman. Then, limitations of these two perspectives were mentioned.

Norouzi (2006) conducted a study aimed to examine the effect of philosophy for children carried out on second- to fifth-grade elementary students using an experimental method within eight months. Results of this study indicated that not only did students develop several abilities including maintaining classroom discipline, respecting people older than themselves, taking responsibilities, being creative, having high levels of selfesteem, and establishing good relationships with others, but also implementing this program was effective in promoting levels of academic achievement among them.

Marashi (2006) carried out a study aimed at investigating the effect of the community of inquiry in philosophy for children on developing reasoning skills among third-grade middle school students. Results of this study demonstrated that conducting this program using a community of inquiry in classrooms positively affected students' reasoning skills.

Eskandari and Kiani (2007), in their empirical study entitled "The Effect of Stories on Increasing Philosophical and Questioning Skills among Students" conducted on a corpus of 60 first-grade high school students using an empirical method, concluded that using philosophical stories led to an improvement in questioning skills and its dimensions including a shift in motivation, change, and doubt in the experimental group.

Naji and Ghazizadeh (2007), in their study entitled "Examining the Results of Philosophy for Children on Reasoning Skills and Behavioral Performance among Children", examined the effect of this program on these two variables which pave the way for promoting and improving their intellectual skills and behavioral performance. In this study conducted using a qualitative method, a workshop, in which the community of inquiry was applied, was carried out for 11 consecutive sessions. Results of this study showed that this program was effective in promoting and improving most of the predicted skills among the students. Improved skills included reasoning, differentiation of similar affairs, good judgment, critical thinking, being creative, and being responsible.

Tabatabaei (2008) demonstrated that philosophy for children had a significant impact on developing the spirit of questioning and critical thinking, increasing interactions among students, developing coping skills, increasing participation, decreasing shyness, enhancing the spirit of criticism, respecting others and having mutual relationships, having intellectual independence, weakening the spirit of confrontation, strengthening self-confidence and power of expression, improving judgment skills, and strengthening argumentation skills.

GhamariGivi et al. (2014), in a study entitled "The Impacts of the Program of Teaching Philosophy for Children on the Skills of Meaningfulness, Tolerance of Ambiguity, Harmony, and Drawing Conclusions in the Development of Students' Critical Thinking" conducted on fifth-grade elementary students in Ilam, concluded that teaching 
philosophy for children had a positive impact on improving critical thinking and its components (meaningfulness, tolerance of ambiguity, harmony, and drawing conclusions).

In another study entitled "The Effect of Conducting the Localized Version of Philosophy for Children on Increasing Self-efficacy, Optimism, and Happiness among Female First-Grade Junior High School Students" carried out in Isfahan, Norouzi and Abedi (2014) jumped into a conclusion that conducting this program had a positive effect on self-efficacy and optimism; however, it was not effective in improving happiness.

\section{Studies Conducted in Other Countries}

Lipman and Birman (1970) assessed philosophy for children for the first time. In their study, they indicated that this 9-week program can have an impact on children's critical thinking and reasoning skills (Tabatabaei, 2008).

Haas (1980) indicated that philosophy for children can bring about dramatic advances in critical thinking and interpersonal relationships among children. In another study carried out on a corpus of 32 fifth-grade elementary school students assigned to an experimental group and a control group (each included 16 students), Cummings (1987) demonstrated that this philosophical approach can improve logical and critical reasoning skills (Tabatabaei, 2008).

Allen (1988) conducted this program on 23 students, as an experimental group, and showed that the students who took part in philosophy for children and adolescents, compared to the control group, had a better performance in reading and perceiving various contents and critical thinking.

Daniel (1989) examined philosophy for children and its effects on critical thinking among students. Results of this study demonstrated that students who participated in the training period carried out between nine and fifteen weeks (two hours a week), compared to the control group, had a better performance in critical thinking skills in a short interview and in filling out a questionnaire on philosophical issues (Naji, 2010).

Dyofd (1994) focused on five-year-old children. In this project, the experimental group was taught philosophy for children for an academic year. Results obtained from this project indicated that some skills, including thinking, listening, language skills, and selfconfidence, were improved among students who were taught philosophy for children (Naji, 2009).

Tricky (2006), in a study entitled "Philosophy for Children: A Systematic Review" carried out on 100 elementary school students during two academic years, showed that teaching philosophy for children led to significant changes in verbal and non-verbal reasoning skills among the students and teachers used twice as many open-answer questions. Furthermore, listening, speaking, questioning, reasoning, reading, writing, perceiving, and behaving skills of the students significantly improved and the time the 
students had to talk in a 5-hour class had increased from $41 \%$ to $66 \%$. Moreover, nearly 6.5 points were added to the children's IQ (Marashi et al., 2008).

In Singapore, Chan Yoke Keng et al. (2007) conducted a study and suggested that students who took part in philosophy for children program, compared to others, had a better performance in critical thinking and creative thinking skills. Additionally, they were able to express their ideas and respect others' opinions.Hana (2007) examined the foundations of Lipman's theory of philosophy for children. This study aimed to determine and identify basic principles of this program based on the philosophy of pragmatics. Hana (2007) pointed out that Lipman's core resources were ideas presented by Dewey, Mead, and Vygotsky. It was mentioned that the main objective of carrying out this study was opening up a new perspective on teaching philosophy for children from a continental point of view (Marashi et al., 2008).

\section{Research Objectives and Hypotheses}

This study aimed to examine the impact of teaching philosophy for children on critical thinking and components of critical openness and reflective skepticism and self-efficacy.

\section{Minor Goals}

1. Examining the impact of teaching philosophy for children on critical thinking among first-grade junior high school students.

2. Examining the impact of teaching philosophy for children on critical openness among first-grade junior high school students.

3. Examining the impact of teaching philosophy for children on reflective skepticism among first-grade junior high school students.

4. Examining the impact of teaching philosophy for children on self-efficacy among first-grade junior high school students.

\section{METHOD}

This quasi-experimental study followed by a pretest-posttest design with a control group. In this study, philosophy for children was conducted on an experimental group. The current study had a statistical population including all 13-year old female junior high school students studying in Khash in the academic year 2017-2018 who were 320 students. Among these students, 54 people were selected as a sample using a convenience sampling method. The reason for choosing these female students as the sample was that based on Iran's cultural condition, girls and boys study in different schools. To select the sample, among all junior high schools in Khash, several schools in which students with different ethnical backgrounds from various parts of the city were studying were chosen. After considering students studying in different schools, three junior high schools, i.e. Mahdieh, Farzanegan, and Zeinabieh, in which students with different ethnical backgrounds were studying were selected. Out of these schools, Zeinabieh, due to its principal's cooperation, was selected as the sample. The mentioned school had 4 first-grade classes. Among these classes, the third class, including 27 students, was randomly chosen as the experimental group and the second class, including 27 students, was randomly selected as the control group. 


\section{Procedure}

Initially, students assigned to the experimental and control groups were examined by a test on critical thinking and self-efficacy. Teaching philosophy for children was carried out in 12 seventy-minute sessions on the experimental group (one session per week). After completing the sessions of teaching philosophy for children, levels of critical thinking and self-efficacy among the students in the experimental and control groups were again assessed in the posttest. To manage these classes, the community of inquiry was used. In the classes, a collection of 10-volume storybooks published for Iranian children by Norouzi and Abedi(2014) was used. A number of these books, entitled "Impatient Pigeon", “A Duck's Mistake", “Adventure of a Peasant and His Son”, and "Custodian Thief", were chosen by the Congress of Servants of Written Culture and they include philosophical and moral contents.

The students read the stories and they were encouraged to ask questions about them. In these sessions, the students expressed their ideas, listened to others' ideas, and asked questions they had. Finally, by reasoning, they gave meanings to abstract concepts.

\section{Measurement Tools}

\section{The Critical Thinking Disposition Scale}

In the current study, the Sosu Critical Thinking Disposition Scale developed in 2013 was used. This scale includes 11 items which examine two main components, i.e. critical openness (items 1 to 7) and reflective skepticism (items 8 to 11). The items are scored based on a 5-point Likert-type scale ranging from 1 (totally disagree) to 5 (totally agree). A total score is obtained by adding scores for each item obtained by a subject and it can range from 11 to 55. Scores from 11 to 34 indicate a weak tendency, scores from 35 to 45 show a moderate tendency, and scores from 45 to 55 demonstrate a high tendency. The other method of scoring these items is based on scores obtained on the components. A total score on critical openness ranges from 7 to 35. Scores from 7 to 21 indicate a low level, scores from 22 to 28 show a moderate level, and scores from 29 to 35 demonstrate a high level. A total score on reflective skepticism ranges from 4 to 20 . Scores from 4 to 12 indicate a low level, scores from 13 to 16 show a moderate level, and scores from 17 to 20 demonstrate a high level (Sharif, 2015).

\section{Reliability of the Critical Thinking Disposition Scale}

In Iran, the validity and reliability of this scale were examined bySharif (2015). Using a confirmatory factor analysis, results of data analyses conducted by Sharif showed that critical thinking, like the original version, includes two components, i.e. critical openness and reflective skepticism. Using a Cronbach's alpha coefficient, results obtained from assessing the scale's validation demonstrated that its coefficient was 0.71 which was acceptable(Sharif, 2015). In addition, in this study, the structural validity and predictive validity of this scale were confirmed.

To examine the reliability of this scale, it was carried out on a corpus of 30 first-grade junior high school students. The alpha coefficient of this scale was 0.77 which indicated that this scale was valid. 


\section{The Self-Efficacy Questionnaire for Children and Adolescents}

In this study, the Self-Efficacy Questionnaire for Children and Adolescents developed by Muris et al. (2001) was applied. This scale was designed to assess levels of selfefficacy among children and adolescents considering three dimensions, i.e. social, academic, and emotional self-efficacy. It includes 23 items scored based on a 5-point Likert-type scale ( $1=$ very low, $2=$ low, $3=$ not low and not high, $4=$ high, and $5=$ very high). The highest score of this scale is 120 and its lowest score is 24 . The more a subject's score, the higher the level of his/her self-efficacy. The lower his/her score, the lower his/her level of self-efficacy.

\section{Reliability oftheSelf-Efficacy Questionnaire for Children and Adolescents}

This questionnaire was conducted on 43 students in Tehran with a two-week interval. Its reliability was 0.87 and its Cronbach's alpha coefficient was 0.74 (Tahmasbian et al., 2005). Furthermore, in this study, the Cronbach's alpha coefficient of this scale was 0.80 which indicated that it was valid.

\section{Data Analyses}

In the present study, the experimental and control groups (each including 27 people) were studied in two stages, i.e. the pretest and posttest. After collecting data, the obtained data were analyzed via SPSSver. 18 and results are presented in the following tables.

In tables 2, 4, 6, and 8, initially, differences between scores obtained by the experimental and control groups in the pretest and posttest were calculated. Afterward, the mean differences between these two groups were calculated using an independent $\mathrm{t}$ test.

Table 1 indicates descriptive indicators of critical thinking based on scores obtained in the pretest and posttest. Table 2 demonstrates results of the independent t-test conducted to examine the impact of teaching philosophy for children on critical thinking among the first-grade junior high school students.

Table 3 indicates descriptive indicators of critical openness based on scores obtained in the pretest and posttest. Table 4 demonstrates results of the independent t-test conducted to examine the impact of teaching philosophy for children on critical openness among the first-grade junior high school students.

Table 5 indicates descriptive indicators of reflective skepticism based on scores obtained in the pretest and posttest. Table 6 demonstrates results of the independent $\mathrm{t}$ test conducted to examine the impact of teaching philosophy for children on reflective skepticism among the first-grade junior high school students.

Table 7 indicates descriptive indicators of self-efficacy based on scores obtained in the pretest and posttest. Table 8 demonstrates results of the independent t-test conducted to examine the impact of teaching philosophy for children on self-efficacy among the firstgrade junior high school students. 


\section{FINDINGS}

Table 1

The descriptive indicators of critical thinking

\begin{tabular}{|c|c|c|c|c|c|c|c|}
\hline & \multicolumn{3}{|c|}{ Pretest } & \multicolumn{3}{|c|}{ Posttest } & \multirow{2}{*}{$\begin{array}{l}\text { Difference between } \\
\text { pretest and posttest scores }\end{array}$} \\
\hline & $\mathrm{N}$ & M & SD & $\mathrm{N}$ & M & SD & \\
\hline Experimental & 27 & 36.15 & 6.37 & 27 & 46.26 & 3.42 & 10.11 \\
\hline Control & 27 & 38 & 8.92 & 27 & 34.33 & 7.83 & -3.67 \\
\hline
\end{tabular}

As can be seen in Table 1, the mean score obtained by the experimental group in the pretest is 36.15 (a weak-to-moderate tendency); however, their mean score in the posttest is 46.26 (a high tendency).This indicates that teaching philosophy for children positively affects the children's critical thinking mean scoreby 10.11 . This is while the mean score of the control group is 38 (a moderate tendency) in the pretest and it is 34.33 (a weak tendency) in the posttest which shows a decrease by 3.67.

Table 2

Results of the independent t-test in relation to the effect of teaching philosophy for children on critical thinking among the students

\begin{tabular}{llllllll}
\hline $\begin{array}{l}\text { Proportionality of the } \\
\text { pretest-posttest scores on } \\
\text { critical thinking }\end{array}$ & Group & $\mathrm{N}$ & $\mathrm{MD}$ & $\mathrm{SD}$ & $\mathrm{T}$ & $\mathrm{df}$ & $\mathrm{Sig}$ \\
\cline { 2 - 8 } & Experimental & 27 & 10.11 & 5.93 & 9.176 & 52 & 0.000 \\
\cline { 2 - 6 } & Control & 27 & -3.67 & 5.07 & & & \\
\hline
\end{tabular}

The results presented in Table 2 demonstrate that the mean difference and standard deviation of critical thinking in the experimental group are 10.11.5.93; however, the mean difference and standard deviation of critical thinking in the control group are $3.67 \pm 5.07$ with a degree of freedom of 52 and an independent t-statistic of 9.176.This is significant at the $99 \%$ confidence level $(\mathrm{P}<0.01)$. Therefore, the null hypothesis is rejected and the alternative hypothesis, i.e. teaching philosophy for children affects critical thinking among students, is confirmed.

Table 3

The descriptive indicators of critical openness

\begin{tabular}{lccccccc}
\hline & \multicolumn{3}{c}{ Pretest } & & Posttest & Difference between pretest \\
\cline { 2 - 7 } & $\mathrm{N}$ & $\mathrm{M}$ & $\mathrm{SD}$ & $\mathrm{N}$ & $\mathrm{M}$ & $\mathrm{SD}$ & and posttest scores \\
\hline Experimental & 27 & 24.41 & 4.63 & 27 & 28.44 & 2.67 & 4.037 \\
\hline Control & 27 & 25.96 & 5.21 & 27 & 22.37 & 5.13 & -3.593 \\
\hline
\end{tabular}

As can be seen in Table 3, the mean score obtained by the experimental group in the pretest is 24.41 (moderate); however, their mean score in the posttest is 28.44 (moderate-to-high).This indicates that teaching philosophy for children positively affects the children's critical openness mean scoreby 4.037. This is while the mean score of the control group is 25.96 (a moderate tendency) in the pretest and it is 22.37 (a moderateto-weak tendency) in the posttest which shows a decrease by 3.593 . 
Table 4

Results of the independent t-test in relation to the effect of teaching philosophy for children on critical openness among the students

\begin{tabular}{llllllll}
\hline $\begin{array}{l}\text { Proportionality of } \\
\text { pretest-posttest scores } \\
\text { on critical openness }\end{array}$ & Group & N & MD & SD & T & df & Sig \\
\cline { 2 - 6 } & Experimental & 27 & 4.037 & 4.839 & 5.989 & 52 & 0.000 \\
\cline { 2 - 5 } & Control & 27 & 3.593 & 4.517 & & & \\
\hline
\end{tabular}

The results presented in Table 4 demonstrate that the mean difference and standard deviation of critical openness in the experimental group are 4.037 44.839 ; however, the mean difference and standard deviation of critical openness in the control group are $3.593 \pm 4.517$ with a degree of freedom of 52 and an independent t-statistic of 5.989. This is significant at the $99 \%$ confidence level $(\mathrm{P}<0.01)$. Therefore, the null hypothesis is rejected and the alternative hypothesis, i.e. teaching philosophy for children affects critical openness among students, is confirmed.

Table 5

The descriptive indicators of reflective skepticism

\begin{tabular}{lllllclc}
\hline & \multicolumn{3}{c}{ Pretest } & & Posttest & \multicolumn{2}{c}{$\begin{array}{c}\text { Difference between } \\
\text { pretest and posttest scores }\end{array}$} \\
\cline { 2 - 8 } & $\mathrm{N}$ & $\mathrm{M}$ & $\mathrm{SD}$ & $\mathrm{N}$ & $\mathrm{M}$ & $\mathrm{SD}$ & 6.741 \\
\hline Experimental & 27 & 11.41 & 2.38 & 27 & 17.81 & 1.42 & -0.482 \\
\hline Control & 27 & 12.93 & 2.42 & 27 & 12.44 & 2.88 & \\
\hline
\end{tabular}

As can be seen in Table 5, the mean score obtained by the experimental group in the pretest is 11.41 (a weak tendency); however, their mean score in the posttest is 17.81 (a high tendency). This indicates that teaching philosophy for children positively affects the children's reflective skepticism mean scoreby 6.741. This is while the mean score of the control group is 12.93(a weak-to-moderate tendency) in the pretest and it is 12.44 (a weak tendency) in the posttest which shows a decrease by 0.482 .

Table 6

Results of the independent t-test in relation to the effect of teaching philosophy for children on reflective skepticism among the students

\begin{tabular}{lrlllllll} 
Proportionality & of & Group & N & MD & SD & T & df & Sig \\
\cline { 2 - 7 } pretest-posttest scores & Experimental & 27 & 6.741 & 2.218 & 10.369 & 52 & 0.000 \\
\cline { 2 - 7 } & Control reflective skepticism & 27 & -0.482 & 2.424 & & & \\
\hline
\end{tabular}

The results presented in Table 6 demonstrate that the mean difference and standard deviation of reflective skepticism in the experimental group are 6.741 \pm 2.218 ; however, the mean difference and standard deviation of reflective skepticism in the control group are $-0.482 \pm 2.424$ with a degree of freedom of 52 and an independent t-statistic of 10.369. This is significant at the $99 \%$ confidence level $(\mathrm{P}<0.01)$. Therefore, the null hypothesis is rejected and the alternative hypothesis, i.e. teaching philosophy for children affects reflective skepticism among students, is confirmed. 
Table 7

The descriptive indicators of self-efficacy

\begin{tabular}{lllllllc}
\hline & \multicolumn{3}{c}{ Pretest } & & Posttest & Difference between \\
\cline { 2 - 7 } & $\mathrm{N}$ & $\mathrm{M}$ & $\mathrm{SD}$ & $\mathrm{N}$ & $\mathrm{M}$ & $\mathrm{SD}$ & pretest and posttest scores \\
\hline Experimental & 27 & 67.22 & 9.94 & 27 & 74.67 & 11.49 & 7.44 \\
\hline Control & 27 & 71.85 & 15.04 & 27 & 68.93 & 15.75 & -2.93 \\
\hline
\end{tabular}

As can be seen in Table 7, the mean score obtained by the experimental group in the pretest is 67.22; however, their mean score in the posttest is 74.67.This indicates that teaching philosophy for children positively affects the children's self-efficacy mean scoreby 7.44. This is while the mean score of the control group is 71.85 in the pretest and it is 68.93 in the posttest which shows a decrease by 2.93 .

Table 8

Results of the independent t-test in relation to the effect of teaching philosophy for children on self-efficacy among the students

\begin{tabular}{lrlllllll}
\hline Proportionality & of & Group & N & MD & SD & T & df & Sig \\
\cline { 2 - 8 } $\begin{array}{l}\text { pretest-posttest } \\
\text { on self-efficacy }\end{array}$ & scores & Experimental & 27 & 7.44 & 7.08 & 3.781 & 52 & 0.000 \\
\cline { 2 - 7 } & Control & 27 & -2.93 & 12.37 & & & \\
\hline
\end{tabular}

The results presented in Table 8 demonstrate that the mean difference and standard deviation of self-efficacy in the experimental group are 7.44 \pm 7.08 ; however, the mean difference and standard deviation of self-efficacy in the control group are $-2.93 \pm 12.37$ with a degree of freedom of 52 and an independent t-statistic of 3.781. This is significant at the $99 \%$ confidence level $(\mathrm{P}<0.01)$.Therefore, the null hypothesis is rejected and the alternative hypothesis, i.e. teaching philosophy for children affects selfefficacy among students, is confirmed.

\section{DISCUSSION AND CONCLUSION}

This study aimed to examine the impact of teaching philosophy for children on critical thinking, its components (critical openness and reflective skepticism), and self-efficacy among the female first-grade junior high school students. The results related to the first hypothesis, i.e. teaching philosophy for children affects critical thinking among the students, indicated that teaching philosophy for children affectedthe levels of critical thinking among the first-grade junior high school students. The results of the present study demonstrated that critical thinking and its components improved the community of inquiry and this method of teaching had a positive impact on the students assigned to the experimental group.

These resultsare in line with the results obtained from the studies conducted byEskandari and Kiani (2007), demonstrating that using philosophical stories led to an improvement in questioning skills and its dimensions including a shift in motivation, change, and doubt in the experimental group, and Naji and Ghazizadeh (2007), which showed that teaching philosophy for children was effective in promoting and improving most of the predicted skills among the students including reasoning, differentiation of similar affairs, good judgment, critical thinking, being creative, and being responsible. 
Furthermore, they are consistent with the results ofTabatabaei (2008) which indicated a significant impact of teaching philosophy for children on developing the spirit of questioning and critical thinking. Moreover, the results of GhamariGivi et al. (2014)whoconcluded that teaching philosophy for children had a positive impact on improving critical thinking and its components (meaningfulness, tolerance of ambiguity, harmony, and drawing conclusions) confirm the results obtained from the current study.

In addition, the results of this study are in line with the results of Lipman and Birman (1970) which indicated that their 9-week program had an impact on children's critical thinking and reasoning skills (Tabatabaei, 2008).Moreover, these results are consistent with the results obtained from the following studies. Haas (1980) showedthat philosophy for children could bring about dramatic advances in critical thinking and interpersonal relationships among children and Cummings (1987) demonstrated that this philosophical approach could improve logical and critical reasoning skills (Tabatabaei, 2008). Furthermore, Allen (1988) showed thatthestudents who took part in philosophy for children and adolescents, compared to the control group, had a better performance in reading and perceiving various contents and critical thinking.Daniel (1989) demonstrated that students who participated in the training period carried out between nine and fifteen weeks (two hours a week), compared to the control group, had a better performance in critical thinking skills in a short interview and in filling out a questionnaire on philosophical issues (Naji, 2010). Furthermore, Dyofd (1994) indicated that some skills, including thinking, listening, language skills, and self-confidence, were improved among students who were taught philosophy for children (Naji, 2009).

In the current study, it was also observed that students' levels of motivation and interest in philosophy for children were different from those of normal classes. In other words, despite the implementation of philosophy for children for seventy minutes, few signs of reluctance and fatigue were observed among the students and, in most cases, the students were eager to continue the discussion for a long period. The students were so passionate about the class that they prepared the classroom before the class. The desire for curiosity and the tendency towards raising questions were strengthened among these students. Moreover, the desires for self-correction, accurate recognition, respect for others, great flexibility, increased self-esteem, and empathy between the teacherstudents, on one hand, and among the students, on the other hand, were seen in the community of inquiry.

The results related to the second hypothesis, i.e. teaching philosophy for children affects self-efficacy among the students, indicated that implementing this program had a positive impact on levels of self-efficacy among the female first-grade junior high school students. To explain this finding, it can be stated that through explaining and discussing their beliefs and opinions, the students who took part in this program, achieve a more precise and obvious view of their abilities and capabilities. They learn how to act patiently and seriously against challenges posed by their teacher and classmates and modify their thoughts in order to achieve their worthwhile goal (i.e. trying to get close to the truth). All these factors are effective in creating self-efficacy among students. Additionally, through learning accurate and precise evaluations and becoming familiar 
with critical thinking, they can evaluate themselves in a good way. This evaluation can aid them to recognize their capabilities and weaknesses and explore methods to deal with their weaknesses and strengths. This may aid them to promote their self-efficacy. The results of this study are consistent with the results of the study carried out by Norouzi and Abedi (2014)which indicated that conducting this program had a positive effect on self-efficacy and optimism; however, it was not effective in improving happiness.

It is necessary that all those involved in the educational system pay great attention to this issue and through applying the results of this study, try to improve teaching methods at schools and to promote critical thinking skills and self-efficacy among students.

Among limitation of the present study, the fact that these results cannot be generalized to male students and age groups different from that considered in this study can be mentioned. Hence, it is recommended that further studies be conducted to examine the impact of teaching philosophy for children in other groups.

\section{REFERENCES}

AbbasiYadkouri, M. (2002). Reviewing the content of social studies in high schools in developing thinking skills based on the social perspective of curriculum planning (MA dissertation). Tehran: AllamehTabatabaei University.

AliniaKarouei, R. (2003). A study on therelationshipbetween general selfefficacyandmentalhealthamongthird-gradehighschoolstudents in Babol in theacademicyear 2002-2003 (MA dissertation). Tehran: AllamehTabatabaeiUniversity.

Allen, T.L. (1988). Doing philosophy with children.Thinking: The Journal of Philosophy for Children, 7(3), 23-28.

Bandura, A. (1977). Thetheory of sociallearning. Tehran: RahgoshaPublication.

Chan Yoke Keng, B. (2007). Philosophy for Children. Singapore: Proceeding of the Redesigning Pedagogy: Culture, Knowledge, and Understanding Conference.

Daniel, M.F. \&Auriac, E. (2011). Philosophy, critical thinking, and philosophy for children. Educational Philosophy and Theory, 43(5), 415-435.

Di Giunta, L., Alessandri, G., Gerbino, M., Kanacri, P.L., Zuffiano, A., \&Caprara, G.V. (2013). The determinants of scholastic achievement: the contribution of personality traits, self-esteem, and academic self-efficacy. Learning and Individual Differences, 27(2), 102-108.

Eskandari, H., \&Kiani, J. (2007). The effect of story on increasing the skill of students' philosophy and inquiry.Quarterly Journal Studies, 7(1), 21-28.

Facione, P.A., Sanches, C.A., Facione, N.C., \&Gainen, J. (1995). The disposition toward critical thinking. Journal of General Education, 44(2), 1-25.

Fatti, L., Motabi, F., Mohammad Khani, Sh., \&KazemzadehAtofi, M. (2006). Life Skills Training: Teacher's Guidebook. Tehran: Danjeh Publication. 
Fisher, R. (2007). Stories for thinking. Tehran: Institute for Human Sciences and Cultural Studies.

Ghaedi, Y. (2007). The possibility of teaching philosophy for children: challenges on the concept of philosophy. Journal of Curriculum Studies, 2(7), 61-94.

GhamariGivi, H., Khaleghkhah, A., Rezaie Sharif, A., \&Zadkhosht, F. (2014). The Impacts of the Program of Teaching Philosophy for Children on the Skills of Meaningfulness, Tolerance of Ambiguity, Harmony, and Drawing Conclusions in the Development of Students' Critical Thinking.Philosophy and Theology, Philosophy and Children, 6(1), 87-10.

Gloudemans, H.A. (2013). Critical Thinking and Self-efficacy: Useful Concepts in Nursing Practice and Education. Ridderkerk: Ridderprint.

Haas, H. (1980). Appendix B: experimental research in philosophy for children. In: M. Lipman, A. M. Sharp \& F. Oscanyon (Eds) Philosophy in the classroom. Philadelphia, PA: Temple University Press.

Hashemiannejad, F. (2001). The presentation of a theoretical framework for a curriculum based on critical thinking in elementary schools with an emphasis on a curriculum of social studies (Ph.D. dissertation). Tehran: Islamic Azad University, Science and Research Branch.

Hatami, H.R., Karimi, Y., \&Nouri, Z. (2010). Teachingphilosohyforchildrenanditsimpact on thedevelopment of emotionalintelligence of Iranianjuniorhighschoolstudents. ThoughtandChildren, 1(2), 22-23.

Jahani, J. (2001). A review of the philosophical foundations of the Lipman educational model of psychology (Ph.D. dissertation). Tehran: University of Tehran.

Lipman, M. (1988). Philosophy Goes to School. Philadelphia, PA: Temple University Press.

Lipman, M. (2003). Thinking in Education. New York: Cambridge University Press.

Marashi, S.M. (2006). Investigating the effect of community of inquiry method in philosophy for children program on the development of reasoning skills among male students in third-grade middle school (Ph.D. dissertation). Ahvaz: ShahidChamran University.

Marashi, S.M., Rahiminasab, H.A., \&Lesani, M. (2008). Feasibility of implementing a program for teaching philosophy for children in elementary school curriculum. Quarterly Journal of Educational Innovations, 28(7), 7-28.

Marashi, S.M., SafaeeMoghaddam, M., \&Khazami, P. (2010). A study of the effects of teaching philosophy by using the community of inquiry method on the moral judgment development in fifth-grade primary school students of Ahvaz. Thinking and Children, $1(1), 83-102$. 
Morehouse, R. (2010). Developing communities of inquiry in the USA: retrospect and prospect. Analytic Teaching and Philosophical Praxis, 30(2), 21-31.

Muris, P., Schmidt, H., Lambrichs, R., \&Meesters, C. (2001). Protective and Vulnerability Factors of Depression in Normal Adolescents. Behavior Research and Theory, 39(1), 555-565.

Myers, Ch. (1995). Teaching critical thinking. Tehran: Samt Publication.

Naji, S. \&Ghazizadeh, P. (2007). Examining the Results of Philosophy for Children on Reasoning Skills and Behavioral Performance among Children. Quarterly Journal of Curriculum Studies, 2(7), 123-150.

Naji, S. (2008). Philosophical inquiry for children and adolescents. Tehran: Institute for Human Sciences and Cultural Studies.

Naji, S. (2010). Philosophical inquiry for children and adolescent: A dialogue with new revolutionary pioneers in education. Tehran: Institute for Human Sciences and Cultural Studies.

Norouzi, R.A.\&Abedi, M. (2014). Stories for Iranian Children 1. Tehran: AmokhteYarmana Press.

Norouzi, R.A. (2006). A study of philosophical work with children from the viewpoint of Isfahan school students.Quarterly Journal of Educational Innovations, 6 (23), 123 146.

Paul, R. \& Elder, L. (2000). Critical thinking: the path to responsible citizenship. High School Magazine, 7(8), 10-15.

Pazouki, F. \&Heidari, A.A. (2011). Determining the philosophical indicators of dialogue in philosophy for children program. Thinking and Child, Institute for Human Sciences and Cultural Studies, 2(2), 3-18.

Pourafkari, N.A. (1997). A comprehensive dictionary of psychology-psychiatry and related fields. Tehran: Nashr-e-Nei Publication.

Pozter, G. J. (1993). Curriculum pattern.Management Season in Education, 3(7), 3839.

Sha'bani, H. \&Bakhtiari, R. (2004). Education and humanization. Quarterly Journal of Educational Innovations, 3(8), 95-105.

Sharif, A.R. (2015). The factor analysis of the approval of the critical thinking stance in students. The Discipline of Child Interpretation, 6(11), 49-66.

Smith, F. (1998). The philosophy of education. Mashhad: Astan-e-QodsRazavi Press.

Sosu, M.E. (2013). The development and psychometric validation of a critical thinking disposition scale. Thinking skills and creativity, 9(1), 107-119. 
Tabatabaei, Z. (2008). The impact of teaching philosophy for children on questioning and critical thinking of Iranian elementary school girls. Thinking and Children, 2(3), 7390.

Tahmasbian, K., Jazaieri, A.R., Mohammad Khani, P., \& Ghazi Tabatabaei, M. (2005).

Direct and indirect effects of social self-efficacy on depression among adolescents. Social Welfare, 19(4), 113-124.

Topping, K. J. \&Trickey, S. (2004). Philosophy for children: a systematic review. Research Papers in Education, 19(3), 365-380. 